\title{
Extraction of Brain Signal during Motor Imagery Task for Wheelchair Control Command
}

\author{
Achmad Nur Aliansyah, Achmad Arifin, Djoko Purwanto, Muhammad Hilman Fatoni
}

\begin{abstract}
Paralysis is a disease that causes loss of function from one or more muscle. When someone is paralyzed, the brain still works to obtain information about body activities. While doing or imagining movement, the similar response occurs in the brain. The purpose of this study was to detect any change the value of Event Related Desynchronization/Event Related Synchronization (ERD/ERS) during event. Time-frequency domain analysis was used to determine the frequency dominant when it occurred. This information would be used as a Band Pass Filter for calculating the value of ERD/ERS. In this research, EEG signals were acquired from channel C3, C3-F3, C4, and C4-F4 base on international system $10 / 20$ from EEG. The findings show that the range of frequency dominant from selected channels on all subject is $8-12 \mathrm{~Hz}$. The value of ERD/ERS was changed $64.43 \%$ in channel $\mathrm{C} 3$ and $60 \%$ in channel C3-F3 whereas in channel C4 was $64.43 \%$ and $66.67 \%$ in channel C4-F4. The change of value of ERD/ERS would be used as control command for wheelchair in the next research topic.
\end{abstract}

Keywords-Brain

Electroencephalography

Desynchronization/Event

Wheelchair.
(BCI),

$$
\text { (EEG), Event Related }
$$

Related Synchronization (ERD/ERS),

\section{INTRODUCTION}

Paralysis is a disease that causes loss of function from one or more muscle. This disease is usually due to stroke, polio, Parkinson's disease, and others which can lose the mobility of upper or lower limb, even both. Paralysis is divided into several types namely monoplegia, diplegia, hemiplegia, paraplegia, and quadriplegia in which each of the five types has different position. Upper limb paralysis causes someone cannot do the activities such as holding, taking, or moving something whereas lower limb paralysis causes someone cannot move from one place to another. Wheelchair is one of tools which could help someone to move when he/she is paralyzed. Wheelchair has been designed to ease the user in controlling the wheelchair, for instance by using joystick as [1] or bio impedance as [2]. However, those could not be used by patients with upper limb paralysis so another alternative is required for the patients.

Brain is a vital organ in human which is the central of

Achmad Nur Aliansyah, Institut Teknologi Sepuluh Nopember (ITS), Indonesia, Aliansyah14@mhs.ee.its.ac.id

Achmad Arifin, Institut Teknologi Sepuluh Nopember (ITS), Indonesia, arifin@bme.its.ac.id

Djoko Purwanto, Institut Teknologi Sepuluh Nopember (ITS), Indonesia djoko@ee.its.ac.id

Muhammad Hilman Fatoni, Institut Teknologi Sepuluh Nopember (ITS) Indonesia, hilmanfatoni@bme.its.ac.id nervous system. Any movements or imagining movements is illustrated clearly in the human brain. The real movement is called Motor Execution (ME) whereas mental representation of a movement without any real movement of the body is called Motor Imagery (MI) [3]. The real or imagining movement has same response in motor imagery. Movement which is done consciously and subconsciously has quite similar mechanism at Motor Imagery. MI processes the picture of movement which will be done without any movement of parts of the body would be seen clearly.

When people are planning and executing movement, there is a change at mu rhythm $(8-12 \mathrm{~Hz})$ and center of beta (13-28 $\mathrm{Hz}$ ) which is called as Event-Related Desynchronization (ERD) and Event-Related Desynchronization (ERS) that play important role in the study of Brain Computer Interface (BCI) [4]. BCI is a kind of communication between brain and limb without normal neural tissue. BCI changes the EEG signal in the form of a reflection of the body activity from central nervous system into a message or command [5].

Over the years, numerous research about BCI have been conducted, such as the application of BCI to navigate a wheelchair as [6] and [7]. The previous research about the EEG signal analysis have been done [8]. That research shows there is a change the value of ERD/ERS during lower limb movement on selected channel. This research continue that research to detect the value of ERD/ERS during subject imagine upper limb movement. That information about value of ERD/ERS which change would be used to control command for wheelchair as an alternative wheelchair navigation for patients with upper limb paralysis.

\section{METHOD}

The process of acquiring signal EEG is done by using Enobio Neuroelectric module with 500 sampling rate per second (SPS). This tool consists of some dry electrode based on 10/20 EEG international system. This EEG communicates via wireless allowing the subjects to be in a comfortable position and also can reduce the effects of electrical interference. There are 3 normal people with the age range from 21-25 years old. The subjects are relaxed sitting on the chair. Each experiment was conducted fifteen times with time duration five minutes. The process of signal acquisition was conducted on channel C3, C3-F3, C4, and C4-F4 as shown in Fig. 1. Filtering process was used to determine the value of ERD/ERS. 


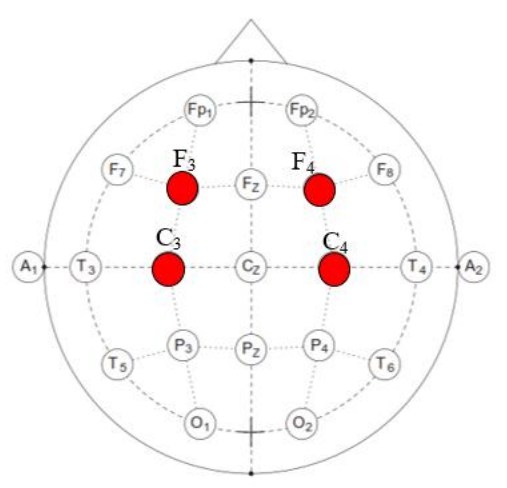

Fig. 1 International system of EEG 10/20.

\section{A. Pre-processing Signal}

The first step after signal acquired was down sampling. The purpose of down sampling was to eliminate interference from unexpected signals. Signals in down sampling by 5 points become $100 \mathrm{~Hz}$ which previously amounts to $500 \mathrm{~Hz}$. After down sampling, Band Pass Filter (BPF) was used to filter the signals. Cut off frequency used is $0.5-30 \mathrm{~Hz}$ based on brain signal frequency range in general. In this research, BPF used consists of Low Pass Filter (LPF) and High Pass Filter (HPF) three-pole Butterworth filter as [9] refer to (1).

$$
\sum_{i=0}^{m=3} C_{i} \cdot X_{k-i}+\sum_{i=1}^{n=3} D_{i} \cdot Y_{k-i}
$$

By using a cut off frequency of LPF $30 \mathrm{~Hz}$ and $\mathrm{HPF} 0.5 \mathrm{~Hz}$, the equation of LPF and HPF is refers to (2) and (3).

$$
\begin{aligned}
& Y[n]=0.257 \cdot X[n]+0.771 \cdot X[n-1]+0.771 \cdot X[n-2]+ \\
& 0.257 \cdot X[n-3]-0.557 \cdot Y[n-1]+0.421 \cdot Y[n-2]+ \\
& 0.056 \cdot Y[n-3] \\
& Y[n]=0.969 \cdot X[n]-0.297 \cdot X[n-1]+2.907 \cdot X[n-2]- \\
& 0.969 \cdot X[n-3]-2.937 \cdot Y[n-1]+2.876 \cdot Y[n-2]+ \\
& 0.939 \cdot Y[n-3]
\end{aligned}
$$

\section{B. Ensemble Average}

In this step, signal acquired from every selected channel would be averaged. There are fifteen signals from the instruction that are averaged into one signal representing the instruction. The result of ensemble average is shown in Fig 2. Grey signal refers to the signal of each instruction and red signal refers to the result of ensemble average.

\section{Short Time Fourier Transform (STFT)}

Short Time Fourier Transform (STFT) is a part of Fourier transformation that is used to determine dominant frequency of a signal. In this research, STFT was used to determine a dominant frequency from the signal of an ensemble average result when the event occurs. Fig 3 shows the result of STFT from an ensemble average.

\section{Determine the Value of ERD/ERS}

In the previous stage, we found a dominant frequency when subject imagine movement. The next step is determining the value of ERD/ERS. By following the standard procedures in determining the value of ERD/ERS from Pfurtscheller and
F.H. Lopez da Silva [10], ERD/ERS was quantified by

1) Band pass filtering for all trials with cut off frequency based on dominant frequency when event occurs,

2) Squaring amplitude from sample to obtain power sample,

3) Averaging the power sample of all trials,

4) Averaging over time to smooth data

Mathematically, ERD/ERS can be quantified refer to (4),

$$
\operatorname{ERD}(\%)=\frac{A-R}{R} \times 100 \%
$$

where, $\mathrm{A}$ is an amplitude of signal, whereas $\mathrm{R}$ is a signal reference. If the value of ERD is positive, the event is ERS, on the contrary if the value of ERD is negative, the event is ERD.
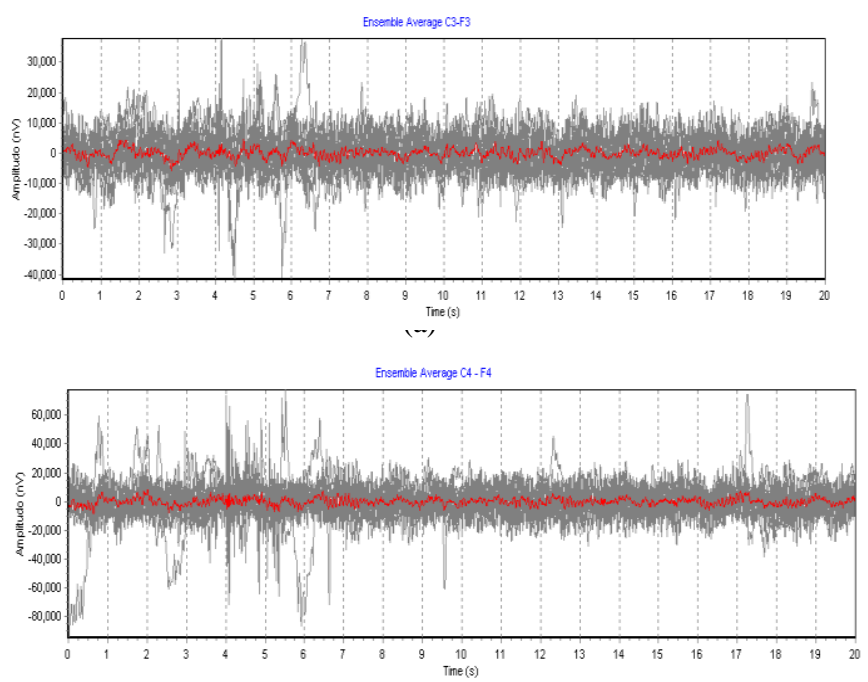

(b)

Fig. 2 (a) Result of ensemble average subject 3 channel C3-F3, (b) result of ensemble average subject 3 channel C4-F4.

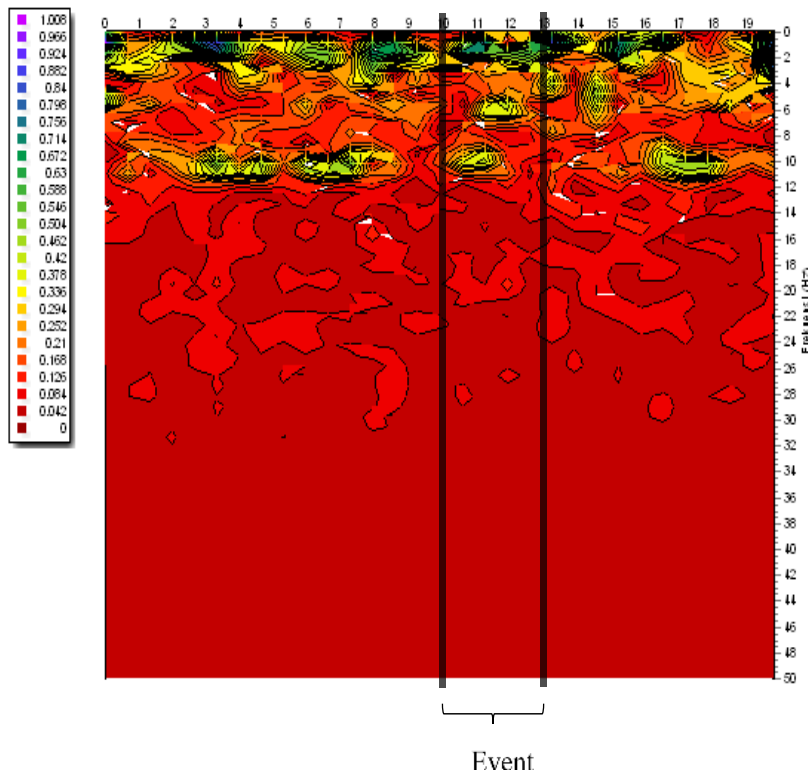

(a) 


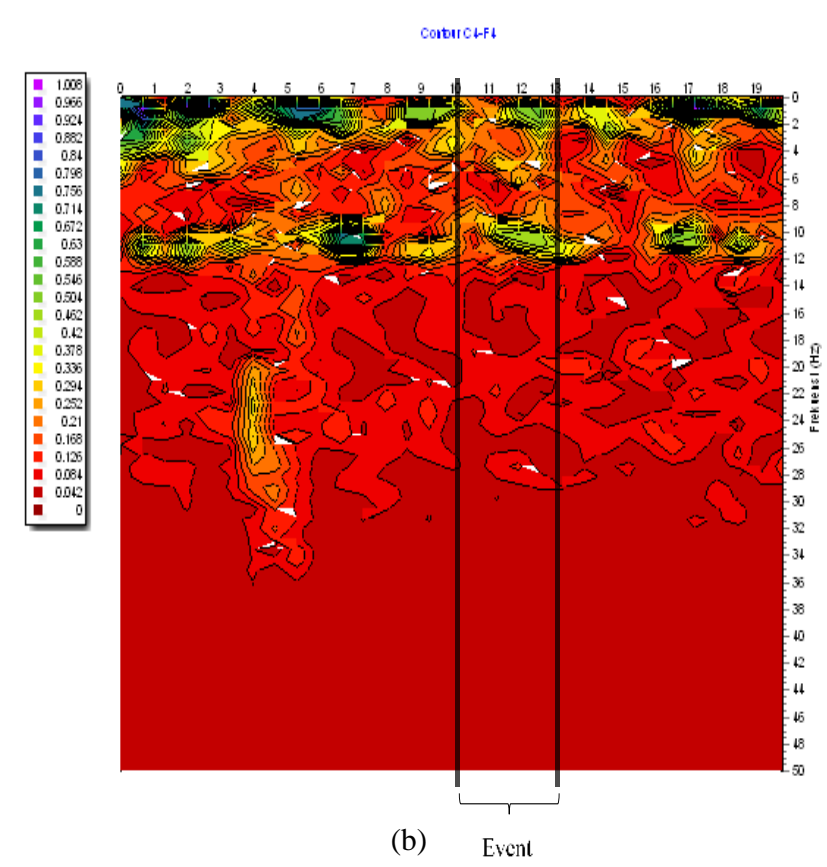

Fig. 3 (a) Result of STFT from subject 3 for channel C3-F3, (b) result of STFT from subject 3 for channel C4-F4.

\section{RESULT}

The result of STFT from ensemble average signal for all subjects show the range of dominant frequency when the subjects try to imagine upper limb movement is $8-12 \mathrm{~Hz}$. Fig 3 shows the result of STFT from one of the subjects. The event is marked by black line (at 10-13 second). Between right hand motor imagery (Fig 3(a)) and left hand motor imagery (Fig 3 (b)) shows the same result.

Fig 4 shows the step of the detection of ERD/ERS. Fig 4(a) shows the raw data from EEG. Fig 4(b) shows the result of $\mathrm{BPF}$ which used frequency dominant as a cut off frequency. In

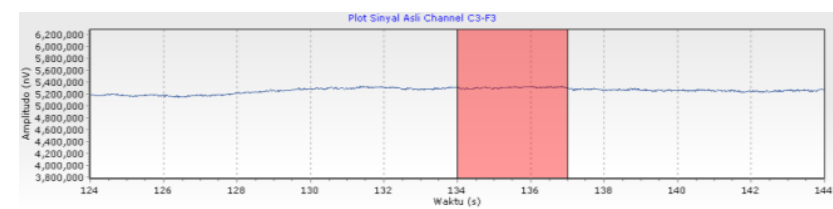

(a)

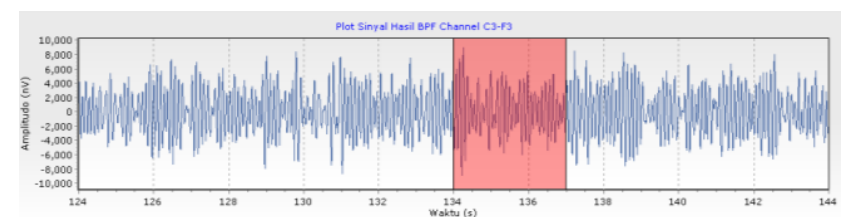

(b)

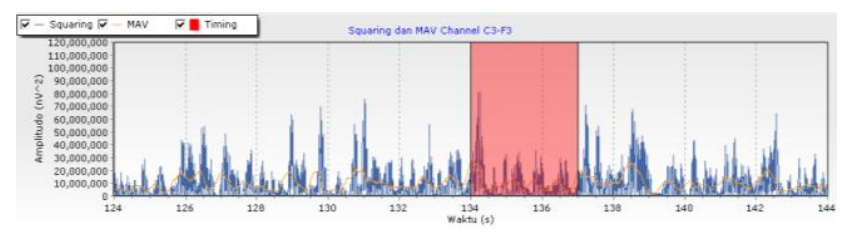

(c)

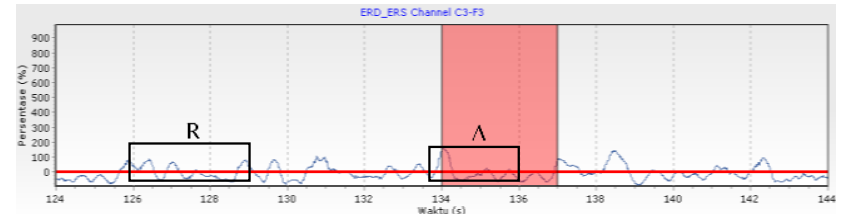

(d)

Fig. 4 Step of the Detection ERD/ERS from subject $2,6^{\text {th }}$ instruction, (a) Raw data from EEG, (b) Result of BPF with cut off frequency 8$12 \mathrm{~Hz}$, (c) Result of squaring and moving average, (d) Detection ERD/ERS

this step, amplitude has decreased. Fig 4(c) shows the squaring of BPF which causes amplitude increasing. Fig 4 (d) shows the signal plot of ERD/ERS. The detection is conducted by using a reference signal $(\mathrm{R})$ at the $2^{\text {nd }}$ till $5^{\text {th }}$ second at the beginning of instruction and a determinant signal ERD/ERS within the frequency band of interest (A) 0.25 second before the event till 2 seconds after the event

Table 1 shows the result of ERD/ERS when the subjects are imagining right hand movement. The success rate for subject 1 for channel $\mathrm{C} 3$ is $53.33 \%$ (8 of 15 instructions) whereas on channel C3-F3 is $66.67 \%$ (10 of 15 instructions). The success rate for subject 2 for channel $\mathrm{C} 3$ is $73.33 \%$ (11 of 15 instructions) whereas on channel C3-F3 is $53.33 \%$ ( 8 of 15 instructions). The success rate for subject 3 for channel c3 is $53.33 \%$ (8 of 15 instructions) whereas on channel $\mathrm{C} 3-\mathrm{F} 3$ is $66.67 \%$ (10 of 15 instructions).

Table 2 shows the result ERD/ERS when the subjects are imagining left hand movement. The success rate for subject 1 for channel $\mathrm{C} 4$ is $66.67 \%$ (10 of 15 instructions) whereas on channel C4-F4 is $60 \%$ (9 of 15 instructions). The success rate for subject 2 for channel $\mathrm{C} 4$ is $73.33 \%$ (11 of 15 instructions) whereas on channel C4-F4 is $80.33 \%$ (12 of 15 instructions). The success rate for subject 3 for channel $\mathrm{C} 4$ is $53.33 \%$ (8 of 15 instructions) whereas on channel C3-F3 is 60\% (9 of 15 instructions).

TABLE I

THE VALUE OF ERD/ERS FOR RIGHT HAND MOVEMENT IMAGERY

\begin{tabular}{|c|c|c|c|c|c|c|}
\hline \multirow{4}{*}{$\begin{array}{c}\text { Instructio } \\
\mathbf{n}\end{array}$} & \multicolumn{6}{|c|}{ Value of ERD/ERS (\%) } \\
\hline & \multirow{2}{*}{\multicolumn{2}{|c|}{$\begin{array}{l}\text { Subject } 1 \\
\text { Channel }\end{array}$}} & \multirow{2}{*}{\multicolumn{2}{|c|}{$\begin{array}{l}\text { Subject } 2 \\
\text { Channel } \\
\end{array}$}} & \multirow{2}{*}{\multicolumn{2}{|c|}{$\begin{array}{c}\text { Subject } 3 \\
\text { Channel }\end{array}$}} \\
\hline & & & & & & \\
\hline & C3 & C3-F3 & C3 & C3-F3 & C3 & $C 3-F 3$ \\
\hline 1 & -78.10 & -53.96 & -58.04 & -24.90 & -26.66 & -32.05 \\
\hline 2 & 19.90 & -69.06 & 56.04 & 55.47 & -0.87 & -13.94 \\
\hline 3 & -11.63 & 259.51 & -43.36 & -3.22 & 9.33 & -3.54 \\
\hline 4 & 7.80 & -5.00 & 72.07 & -97.58 & -31.02 & -3.90 \\
\hline 5 & -63.61 & -64.83 & -0.73 & $\begin{array}{l}262.0 \\
1\end{array}$ & 40.93 & -52.95 \\
\hline 6 & -8.21 & -88.50 & -22.19 & 21.99 & -8.33 & -39.72 \\
\hline 7 & -32.82 & $\begin{array}{l}1178.4 \\
7\end{array}$ & -3.74 & -31.59 & -25.16 & 0.07 \\
\hline 8 & 5.04 & 36.20 & -16.37 & 22.97 & -16.02 & $\begin{array}{l}222.5 \\
7\end{array}$ \\
\hline 9 & $\begin{array}{l}194.1 \\
7\end{array}$ & 128.32 & -24.12 & -11.05 & 99.35 & $\begin{array}{l}234.2 \\
5\end{array}$ \\
\hline 10 & -43.51 & -77.22 & -36.48 & $\begin{array}{l}158.6 \\
4 \\
\end{array}$ & -38.41 & -49.24 \\
\hline 11 & 1.80 & -72.65 & -39.98 & 59.49 & -1.16 & $\begin{array}{l}126.4 \\
2 \\
\end{array}$ \\
\hline 12 & -11.15 & -22.54 & -24.43 & -87.27 & -18.23 & -23.19 \\
\hline
\end{tabular}




\begin{tabular}{|c|l|l|l|l|l|l|}
13 & 25.48 & 14.82 & 93.99 & -20.93 & 6.66 & -50.16 \\
\hline 14 & -9.49 & -40.23 & -1.38 & -6.33 & -38.94 & 35.28 \\
\hline 15 & 43.36 & -10.88 & 32.88 & $\begin{array}{l}112.9 \\
4\end{array}$ & 15.39 & 57.41 \\
\hline $\begin{array}{l}\text { Successful } \\
\text { rate (\%) }\end{array}$ & 53.33 & 66.67 & 73.33 & 53.33 & 66.67 & 60 \\
\hline
\end{tabular}

TABLE II

THE VALUE OF ERD/ERS FOR LEFT HAND MOVEMENT IMAGERY

\begin{tabular}{|c|c|c|c|c|c|c|}
\hline \multirow{4}{*}{$\begin{array}{c}\text { Instructio } \\
\mathbf{n}\end{array}$} & \multicolumn{6}{|c|}{ Value of ERD/ERS (\%) } \\
\hline & \multirow{2}{*}{\multicolumn{2}{|c|}{$\begin{array}{l}\text { Subject } 1 \\
\text { Channel }\end{array}$}} & \multirow{2}{*}{\multicolumn{2}{|c|}{$\begin{array}{l}\text { Subject } 2 \\
\text { Channel }\end{array}$}} & \multirow{2}{*}{\multicolumn{2}{|c|}{$\begin{array}{l}\text { Subject } 3 \\
\text { Channel }\end{array}$}} \\
\hline & & & & & & \\
\hline & C4 & C4-F4 & C4 & C4-F4 & $C 4$ & C4-F4 \\
\hline 1 & 54.48 & 5.35 & -35.11 & -2.44 & -75.07 & -68.52 \\
\hline 2 & 23.79 & -9.81 & 67.44 & 90.48 & 62.82 & 167.24 \\
\hline 3 & -49.40 & -69.80 & -42.42 & -53.25 & -46.60 & -19.15 \\
\hline 4 & -19.29 & -48.91 & -23.18 & -17.57 & 77.37 & -6.37 \\
\hline 5 & -67.65 & -97.24 & -10.56 & -42.64 & -62.77 & -51.69 \\
\hline 6 & -11.47 & $\begin{array}{l}415.8 \\
1\end{array}$ & 55.86 & -7.92 & 13.62 & 24.10 \\
\hline 7 & -14.97 & -72.87 & -37.49 & -61.83 & -39.44 & -27.55 \\
\hline 8 & $\begin{array}{l}169.8 \\
0\end{array}$ & $\begin{array}{l}542.3 \\
3 \\
\end{array}$ & -26.09 & -49.76 & 3.74 & -40.66 \\
\hline 9 & 74.92 & $\begin{array}{l}608.3 \\
7 \\
\end{array}$ & -3.21 & -65.54 & -8.27 & 0.99 \\
\hline 10 & -2.35 & 30.76 & 1.86 & -18.55 & -2.16 & -27.71 \\
\hline 11 & 7.51 & -56.45 & -19.60 & 21.42 & -42.39 & -28.05 \\
\hline 12 & -18.82 & -78.16 & -20.82 & 5.74 & 40.71 & 142.88 \\
\hline 13 & -10.12 & -80.39 & -61.08 & -51.09 & $\begin{array}{l}165.7 \\
2\end{array}$ & 231.81 \\
\hline 14 & -8.16 & 50.25 & -32.48 & -86.61 & -35.74 & -32.19 \\
\hline 15 & -77.68 & -87.75 & 21.60 & -6.32 & $\begin{array}{l}116.6 \\
1 \\
\end{array}$ & 455.30 \\
\hline $\begin{array}{l}\text { Successful } \\
\text { rate }(\%)\end{array}$ & 66.67 & 60 & 73.33 & 80 & 53.33 & 60 \\
\hline
\end{tabular}

\section{CONCLUSION}

In this research, extraction of brain signal during motor imagery task for wheelchair control command was performed. The findings show that dominant frequency when the event occurs is $8-12 \mathrm{~Hz}$. Based on the experiment, right hand movement imagery for subject 1 channel C3-F3 have a higher success rate detection compared to channel $\mathrm{C} 3$, while for subject 2 and subject 3 channel $\mathrm{C} 3$ have a higher success rate than channel C3-F3. For left hand movement imagery, the success rate detection for subject 1 channel $\mathrm{C} 4$ have a higher success rate than channel C4-F4, while for subject 2 and subject 3 channel $\mathrm{C} 4-\mathrm{F} 4$ have a higher success rate than channel $\mathrm{C} 4$. The value of ERD/ERS was changed on higher success rate would be used as control command for wheelchair in the next research topic. The topic will be addressed in the next research activities.

\section{ACKNOWLEDGMENT}

This research is partially supported by ITS Excellent Research Program. The author would like to thank Mr. Achmad Arifin, Ali Z., Fathan, and Gamma for their support and involvement in experiment.

\section{REFERENCES}

[1] R. Yassine, M. Makrem, F. Farhat, and G. Philipe, "Intelligent joystick for controlling power wheelchair navigation", International Conference on System and Control, vol. 3, submitted for publication.

[2] J. Sardi, "Development of bioelectrical impedance for speed adjustment motion control command wheelchairs with hierarchy control method ", Thesis., Institut Tekonologi Sepuluh Nopember, Surabaya. 2013.

[3] R. Dickstein, and J. E. Deutsch, "Motor Imagery in Physical Therapist Practice", Physical therapy journal, Vol. 87, 2007, pp. 942-953.

[4] M. Lotze, H. Ulrike. "Motor Imagery". Journal of Physiology, vol. 99, 2006, pp. 386-395. https://doi.org/10.1016/j.jphysparis.2006.03.012

[5] J. R. Wolpaw, N. Birbaumer, D. J. Mc Farland, G. Pfurstcheller, T. M. Vaughan, "Brain-computer interfaces for communication and control". Clinical Neurophysiology 113, 2002, pp. 767-791. https://doi.org/10.1016/S1388-2457(02)00057-3

[6] D. M. Anousouya, R. Sharmila, and V. Saranya, "Hybrid brain computer interface in wheelchair using voice recognition sensor", International Conference on Computer Communication and Informatics (ICCCI), 2014, submitted for publication. https://doi.org/10.1109/iccci.2014.6921754

[7] G. N. Jayabhavani, N.R. Raajan, and R. Rubini, "Brain mobile interfacing (BMI) system embedded with wheelchair", proceeding of IEEE conference on information and communication technologies (ICT 2013), 2013, pp. 1129-1133.

[8] M. H. Fatoni, E. Wiantara, A. Arifin, "EEG signal analysis during lower limb movement as control command for a rehabilitation of patient poststroke," in national seminar of biotechnology, Surabaya, 2014. submitted for publication

[9] G. Alarcon, C.N. Guy, C.D. Binnie, "a Simple algorithm for a digital three-pole Butterworth filter of arbitrary cut-off frequency: application to digital electroencephalography", Journal of neuroscience methods 104, 2000, pp. 35-44. https://doi.org/10.1016/S0165-0270(00)00324-1

[10] G. Pfurtcheller, F.H. L. da Silva, "Event-related EEG/MEG synchronization and desynchronization: basic principles", Clinical Neurophysiology, vol. 110, 1999, pp. 1842-1857. https://doi.org/10.1016/S1388-2457(99)00141-8 